\title{
REVIEW
}

\section{The rise and fall of $\beta$-agonists in the treatment of ARDS}

\author{
Christopher R Bassford', David R Thickett² and Gavin D Perkins* \\ This article is one of eleven reviews selected from the Annual Update in Intensive Care and Emergency Medicine 2012 (Springer Verlag, \\ DOI: 10.1007/978-3-642-25716-2) and co-published as a series in Critical Care. Other articles in the series can be found online at \\ http://ccforum.com/series/annualupdate2012. Further information about the Annual Update in Intensive Care and Emergency Medicine is \\ available from http://www.springer.com/series/8901.
}

\section{Introduction}

The acute respiratory distress syndrome (ARDS) is a severe inflammatory condition of the lung, which can be triggered by a number of different pulmonary and extrapulmonary insults [1]. The characteristic pathological changes of ARDS include an exudative phase, with the accumulation of fluid within the lung, the release of proinflammatory cytokines and infiltration of inflammatory cells, especially neutrophils, into the lung parenchyma. Damage to the alveolar epithelium and pulmonary capillary endothelium occur and patients develop the characteristic histological appearance of diffuse alveolar damage [1]. This manifests clinically as non-cardiogenic pulmonary edema, which reduces lung compliance and impairs gas exchange.

Pharmacological interventions to date have had limited success in improving outcomes [2]. Improvements to supportive care (protective ventilation [3] and conservative fluid management [4]) are thought to have contributed to the improved outcomes observed in recent years [5]. $\beta$-adrenoceptor agonists ( $\beta$-agonists) are well established in the treatment of airflow obstruction. In addition to actions as bronchodilators, they have anti-inflammatory properties, promote the clearance of alveolar fluid, and promote epithelial and endothelial repair [6]. The scientific rationale for a potential role in the treatment of ARDS is summarized in Figure 1. The clinical effectiveness of $\beta$-agonists has been the subject of clinical trials spanning the last 25 years. Despite early studies showing promise, two large scale randomized controlled trials have recently been terminated on the basis of futility and

${ }^{*}$ Correspondence: g.d.perkins@warwick.ac.uk

${ }^{3}$ Lung Injury and Fibrosis Treatment Program, School of Clinical and Experimental Medicine, University of Birmingham, Birmingham, B15 2TH, UK

Full list of author information is available at the end of the article concerns about safety. In this review, we will outline the pre-clinical evidence for $\beta$-agonists and discuss the results of recent clinical trials.

\section{The $\beta$-adrenoceptor in the lung}

The $\beta$-adrenoceptor is a transmembrane G-proteincoupled receptor linked to adenylate cyclase (AC). Activation of the $\beta$-adrenoceptor stimulates an increase in the production of cAMP from adenosine triphosphate by this enzyme [7]. There are three distinct $\beta$-adrenoceptor subtypes: $\beta 1, \beta 2$ and $\beta 3$, with different distributions, effects and genetics. $\beta 1$ receptors are primarily present within the heart, and $\beta 3$ receptors present principally in adipocytes, but also found on lung endothelial cells. $\beta 2$ receptors are the most important pulmonary adrenoceptor subtype, present in increasing numbers with each generation of airway branching; greatest amounts are, therefore, present in the distal airways and alveoli where they are expressed on the surface of alveolar type I and type II cells [8].

\section{$\beta$-agonists improve alveolar fluid clearance}

The presence of non-cardiogenic pulmonary edema is central to the pathophysiology and outcome of ARDS [9]. The most well studied mechanism for the clearance of alveolar fluid is the active transport of ions across the alveolar epithelium, creating an osmotic gradient for the subsequent movement of fluid. There is good evidence that transported sodium ions are the main driver for this process, entering the alveolar cell through amiloridesensitive $\mathrm{Na}^{+}$channel $(\mathrm{ENaC})$ or other cationic channels on the apical alveolar cell surface, and actively transported out by $\mathrm{Na}^{+}-\mathrm{K}^{+}$-ATPase on the basal surface [10]. The role of chloride ions is less well characterized; although they must follow sodium ions to maintain electro-neutrality, the pathway through which they move 


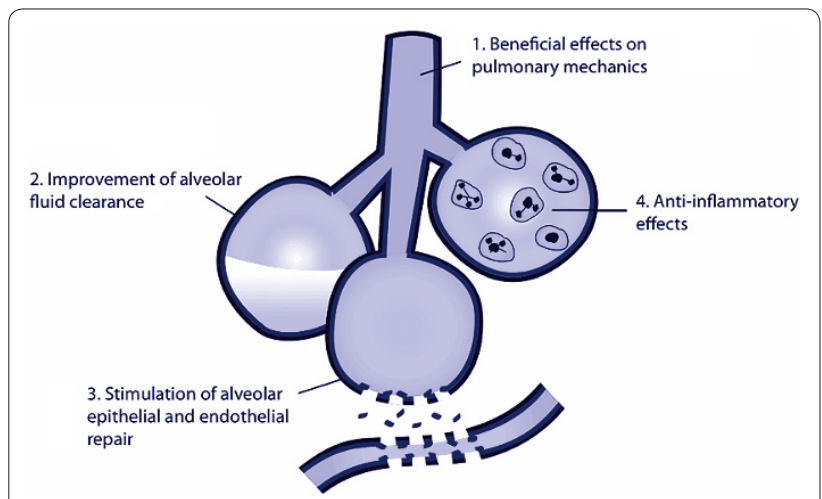

Figure 1. Schematic diagram showing potential therapeutic effects of $\beta$-agonists in acute respiratory distress syndrome (ARDS).

is as yet unidentified. Until recently, alveolar type II cells were thought to be responsible for the majority of ion transport. Sodium and chloride channels have recently been found on the more numerous alveolar type I cells, which may indicate a significant functional role. A contribution to this process may also be made by the distal airway epithelium.

$\beta$-agonists up-regulate the transport of both sodium and chloride ions through the increase in intracellular cAMP caused by $\beta$-adrenoceptor stimulation. A number of mechanisms have been proposed by which ion transport is increased by raised cAMP levels, including a greater sodium channel open probability, changes in the phosphorylation of the $\mathrm{Na}^{+}-\mathrm{K}^{+}$-ATPase $\alpha$-subunit, greater delivery of $\mathrm{ENaC}$ and $\mathrm{Na}^{+}-\mathrm{K}^{+}$-ATPase, and increased chloride transport by the cystic fibrosis transmembrane conductance regulator $[6,10]$.

A higher rate of alveolar fluid clearance following $\beta$ agonist administration has been demonstrated in a number of experimental animal models [6], as well as the ex vivo human lung [11]. Additionally, over-expression of the epithelial $\beta$-adrenoceptor induced a higher rate of lung edema clearance in a rat lung injury model, increasing sensitivity to endogenous catecholamines [12].

\section{The anti-inflammatory effects of $\boldsymbol{\beta}$-agonists}

There is a well recognized interaction between the sympathetic nervous system and the immune response, and $\beta$-adrenoceptors are present on many of the cells that have relevance in the development of ARDS, including macrophages, T-lymphocytes and neutrophils. ARDS is usually associated with an intense alveolar neutrophilia. Neutrophils migrate into the lungs, within hours of the causative insult, and their numbers correlate with severity of disease, and with mortality when persistently high numbers are seen [13]. $\beta$-agonists decrease neutrophil-related inflammation, and this may therefore confer a therapeutic benefit [6,14]. $\beta$-agonists reduce neutrophil adhesion to bronchial epithelial and endothelial cells [15], which may contribute to the reduced neutrophil accumulation within the alveolar space. $\beta$ agonists also decrease neutrophil production of cytotoxic reactive oxygen species (ROS) in vitro. In a human model of acute lung injury (ALI), pre-treatment of health volunteers with inhaled salmeterol prior to lipopolysaccharide (LPS) inhalation attenuated neutrophil infiltration into the lung, myeloperoxidase (MPO) release and tumor necrosis factor (TNF)- $\alpha$ production [16].

Pro-inflammatory stimulation in the pathogenesis of ARDS is mediated within individual cells through the transcription factor, nuclear factor $-k B(N F-k B)$. This cytosolic protein relocates to the nucleus under the influence of pro-inflammatory cytokines, where it binds to specific regions of DNA and in so doing increases the transcription of various inflammatory gene products. To allow movement into the nucleus, the endogenous inhibitor of this protein; inhibitor- $\mathrm{kB}(\mathrm{I}-\mathrm{\kappa} \mathrm{B})$, must dissociate from the protein. During tissue inflammation cytosolic levels of $\mathrm{I}-\mathrm{k} B$ decrease and increased activity of $\mathrm{NF}-\mathrm{kB}$ is seen. This decrease in I- $\mathrm{kB}$ levels is reversed by the action of $\beta$-agonists. In the setting of LPS stimulation of human mononuclear cells, $\beta$-agonists act in a protein kinase A and cAMP dependent manner to increase cytosolic $\mathrm{I}-\mathrm{kB}$ and thereby inhibit the pro-inflammatory action of NF-kB [17].

The interaction between $\beta$-agonists and the inflammatory response is, however, not straightforward. Although in the presence of inflammation, $\beta$-agonists have antiinflammatory properties, in the absence of pro-inflammatory stimulation they themselves can be pro-inflammatory. In vitro, unstimulated macrophages exposed to $\beta$-agonists, increase their production of pro-inflammatory cytokines, such as interleukin (IL)-1 $\beta$ and IL-6 [18]. Increases in inflammatory mediator concentrations are also seen in $\beta$-agonist stimulation of skeletal muscle, fibroblasts and adipocytes, through $\beta$-adrenoceptor and non- $\beta$-adrenoceptor pathways.

\section{$\beta$-agonist effects on alveolar epithelial and endothelial repair}

The alveolar capillary barrier is comprised of the capillary endothelium, the interstitial space including the basement membrane and the extracellular matrix, and the alveolar epithelium. During ALI there is significant damage to all three structures. The clinical importance of this is highlighted by the findings that markers of endothelial damage (von Willebrand factor [vWF]) and epithelial cell damage (KL-6 or receptor for advanced glycation end products [RAGE]) are elevated in those who die from ARDS. Efficient alveolar epithelial repair is therefore important for ARDS patients' recovery. 
Several different lines of research suggest that $\beta$ agonists may reduce endothelial damage or enhance repair in models of lung injury. Evidence for endothelial protection comes from the findings that in experimental acid-induced lung injury, $\beta$-agonists and cAMP donors significantly reduced lung endothelial cell permeability. In vitro thrombin-induced pulmonary endothelial permeability is reduced by $\beta$-agonists by directly maintaining actin filaments and the shape of endothelial cells [19]. Ischemia-reperfusion injury of the pulmonary endothelium is attenuated by agents that increase intracellular cAMP such as $\beta$-agonists, a feature that is of specific interest in the prevention of damage to the lung in nonheart beating organ donation, but is also relevant to all conditions that involve injury to the alveolar-capillary membrane [20].

Evidence for a role of $\beta$-agonists in epithelial repair comes from in vitro studies showing that $\beta$ agonists stimulate the closure of mechanically induced wounds of epithelial monolayers by increasing CAMP and activating protein kinase A (PKA). Incubating bronchoalveolar lavage (BAL) fluid from patients with ARDS who had received treatment with intravenous salbutamol enhanced in vitro epithelial wound repair [21].

\section{Clinical studies of $\boldsymbol{\beta}$-agonists in ARDS Early studies}

The key elements of each trial are summarized in Table 1. The first clinical trial of $\beta$-agonists took place over 25 years ago. Basran et al. conducted an open label trial which examined the effect of a $7 \mu \mathrm{g} / \mathrm{kg}$ infusion of terbutaline on lung vascular permeability in 10 ventilated patients with ARDS [22]. Lung vascular permeability was measured by recording the pulmonary accumulation of radio-labelled transferrin. There was no overall change in lung vascular permeability; however, the five patients who demonstrated a reduction in plasma protein accumulation index survived as opposed to the five patients who showed no improvement (or worsening) of plasma protein accumulation index.

Subsequent trials focused on the effects of $\beta$-agonist therapy on pulmonary mechanics. The increase in cAMP levels caused by $\beta$-adrenoceptor stimulation promotes bronchial smooth muscle relaxation which results in bronchodilation, reducing airways resistance and the pressures required for adequate mechanical ventilation. Pesenti et al. studied the effect of an intravenous infusion of salbutamol in seven mechanically ventilated, paralyzed patients with ARDS [23]. Inspiratory resistance (maximal [total] and minimum [ohmic airway resistance]) and respiratory system compliance were measured at different levels of positive end-expiratory pressure (PEEP) before and 30 minutes after a continuous intravenous infusion of $15 \mu \mathrm{g} / \mathrm{min}$ salbutamol. Treatment with salbutamol reduced maximum and minimum inspiratory resistances (from $6.48 \pm 2.56$ to $4.67 \pm 1.74$ and from $4.06 \pm 2.12$ to $2.07 \pm 0.95 \mathrm{cmH}_{2} \mathrm{O} / \mathrm{l} / \mathrm{sec}$, respectively) but had no effect on effective additional resistance or respiratory system compliance.

Wright et al. conducted the first randomized controlled crossover trial of $\beta$-agonists in the treatment of ARDS [24]. In this study, eight patients with ARDS were randomized to receive $1 \mathrm{ml}$ of $0.5 \%$ metaproterenol solution mixed with $3 \mathrm{ml}$ of normal saline solution, or $4 \mathrm{ml}$ solution of normal saline solution (placebo). Six hours later, treatment arms were crossed over and the opposite regime administered to the same patient. Lung mechanics, shunt fraction, dead space and oxygenation were measured at baseline, 30, 60 and 120 minutes. Aerosolized metaproterenol promptly reduced peak and plateau airway pressure and airway resistance whereas dynamic compliance increased. The effects persisted over the 2 hours of the study. Total compliance also increased as did oxygenation but the changes did not reach statistical significance. There was no effect on minute ventilation, pulmonary shunt fraction or deadspace.

In a subsequent cohort study, the effect of $1 \mathrm{mg}$ nebulized salbutamol was examined in 11 patients with ARDS [25]. Compared to baseline, nebulized salbutamol was associated with modest reduction in peak and plateau airway pressures $\left(4.9 \pm 0.8 \mathrm{cmH}_{2} \mathrm{O}\right.$ and $2.1 \pm 0.6 \mathrm{cmH}_{2} \mathrm{O}$, respectively), intrinsic $\operatorname{PEEP}\left(1.9 \pm 0.5 \mathrm{cmH}_{2} \mathrm{O}\right)$ and minimal respiratory resistance $\left(1.9 \pm 0.3 \mathrm{cmH}_{2} \mathrm{O} / \mathrm{l} / \mathrm{s}\right)$. Additional resistance, static compliance, oxygenation, heart rate and blood pressure did not change.

\section{Recent studies}

A retrospective chart review of 86 adult patients with ALI found that patients with ALI who also received high dose nebulized salbutamol (2.5-6.4 mg/day) had significantly more days alive and free of ALI $(n=22,12.2$ [4.4] days) compared with the group receiving $\leq 2.4 \mathrm{mg} /$ day ( $\mathrm{n}=64,7.6$ [1.9] days). There were no differences in nonpulmonary organ failure or hospital mortality rates $(48 \%$ vs 50\%) [26]. After adjustment for differences in case mix between the groups, high dose salbutamol remained independently associated with the number of days alive and free of ALI in a multivariate model.

The $\beta$-agonist Lung Injury Trial (BALTI-1) [27] was a phase II prospective randomized, double blind, placebocontrolled and the first study in humans to evaluate the effect of $\beta$-agonists on lung water. This single center study randomized 40 adult patients with ARDS to an intravenous infusion of salbutamol $15 \mu \mathrm{g} / \mathrm{kg} / \mathrm{hr}$ for 7 days and serially recorded the effect on extravascular lung water (EVLW). The study demonstrated that salbutamol significantly reduced lung water at day 7 (mean [SD] 9.2 [6] vs. $13.2[3] \mathrm{ml} / \mathrm{kg}, \mathrm{p}=0.038$ ), alveolar capillary permeability 


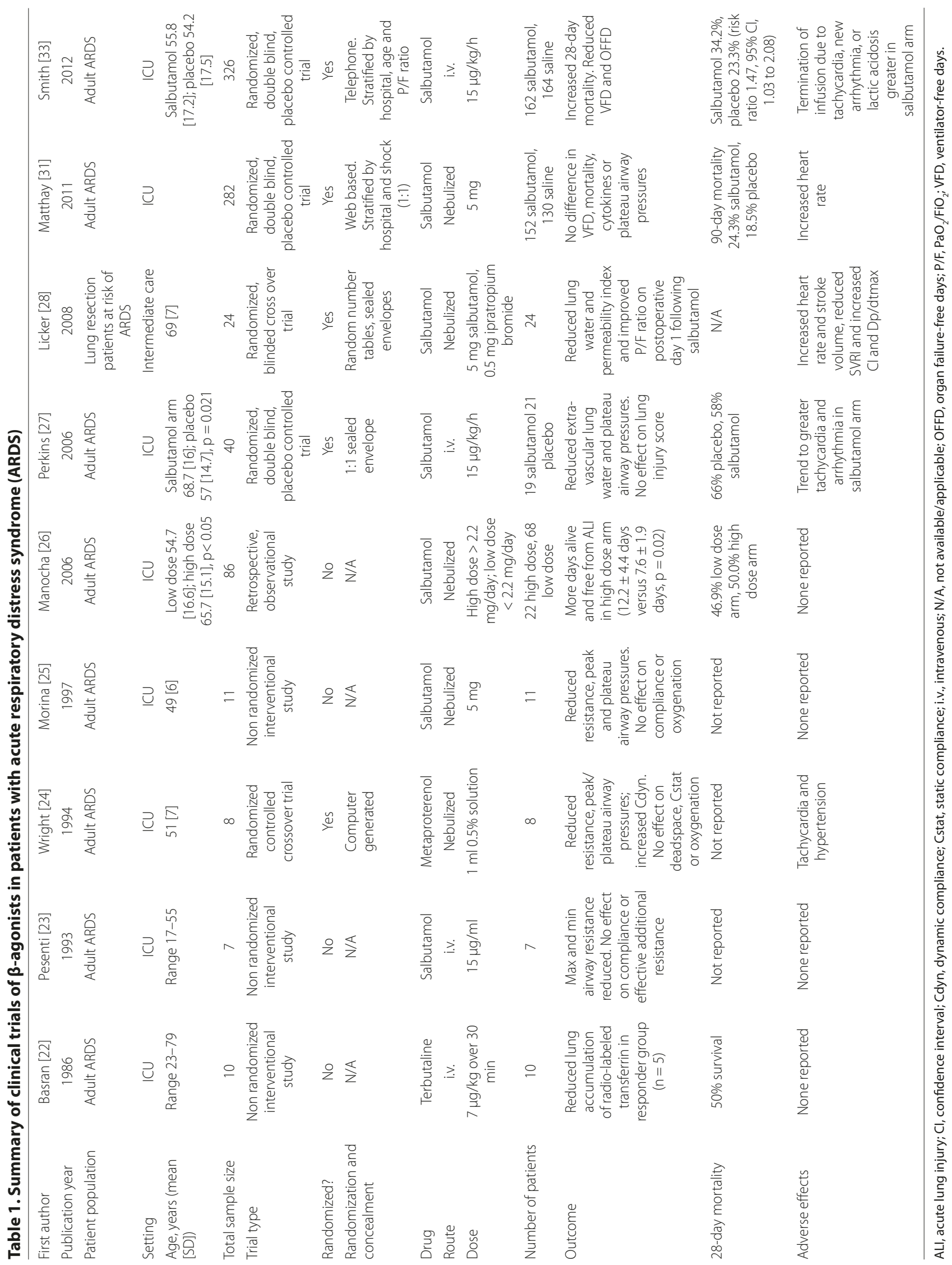


[21] and plateau airway pressures compared to placebo and showed a trend towards reduced lung injury score (LIS). There were no differences in alveolar neutrophil sequestration or inflammatory cytokines [14]. The study protocol included a dose titration algorithm in the event of new onset tachycardia or arrhythmia. Nineteen patients received intravenous salbutamol for a total of 2,148 hours. Five patients in the salbutamol arm developed new onset of supraventricular arrhythmia compared to two patients in the placebo group $(p=0.2)$. No patients sustained serious ventricular arrhythmias. Heart rates were higher in the salbutamol group (average difference at day 1 of 11 beats per min [bpm]) although this was not statistically significant. There were no substantial differences in electrolyte or lactate concentrations between salbutamol and placebo arms.

Licker et al. examined the use of nebulized salbutamol compared to ipratropium bromide in a randomized controlled crossover trial in 21 patients following lung resection who were at risk of, but had not developed ALI [28]. These authors found a significant reduction in EVLW, pulmonary vascular permeability index and an improvement in $\mathrm{PaO}_{2} / \mathrm{FiO}_{2}$ ratio and increased cardiac output on the first postoperative day in the salbutamol arm. The authors concluded that aerosolized salbutamol accelerates the resolution of lung edema, improves blood oxygenation, and stimulates cardiovascular function after lung resection in high-risk patients. Although EVLW has been shown to be an independent predictor of outcome in ARDS [29], its use as a trial outcome has been criticized as decreases in lung perfusion because of worsening disease and non-linear thermal wash-out present in heterogeneously diseased lung may be erroneously interpreted as an improvement in lung edema [30].

The AlbuteroL for the Treatment of ALI (ALTA) study was a multicenter, randomized controlled trial of nebulized salbutamol in patients with ALI run by ARDSnet investigators [31]. This double blind, placebo controlled trial allocated patients to receive either salbutamol $5 \mathrm{mg}$ every four hours or saline placebo for up to 10 days. The primary outcome for the trial was ventilator-free days. The trial started in August 2007 and set out to recruit up to 1000 patients with ALI. The trial was terminated by the Data Monitoring and Safety Board on the grounds of futility after 282 patients had been enrolled. There were no significant differences in the number of ventilator-free days between salbutamol and placebo arms (14.4 vs 16.6 days, $95 \%$ confidence interval $[\mathrm{CI}]$ difference -4.7 to 0.3 days, $\mathrm{p}=0.087)$. There was no difference in hospital mortality rates $(23.0$ and $17.7 \%$; $95 \%$ CI difference -4.0 to $14.7 \%, \mathrm{p}=0.30$ ). There were no differences in plateau airway pressure, minute ventilation or oxygenation index between groups. Although heart rates were significantly higher in the salbutamol arm (average $4 \mathrm{bpm}$ ), there was no difference in rates of new atrial fibrillation (10\% in both groups) or other cardiac arrhythmias. There were no differences in IL- 6 and IL-8 at baseline or on day 3 .

The BALTI-2 trial $[32,33]$ sought to extend the results of BALTI-1 and determine whether treatment with intravenous salbutamol $(15 \mu \mathrm{g} / \mathrm{kg} / \mathrm{h})$ early in the course of ARDS would improve clinical outcomes. The trial commenced in December 2006 with the target of recruiting 1334 patients but was terminated in March 2010 due to safety concerns after the second interim analysis showed a significant $(p=0.02)$ adverse effect of salbutamol on 28-day mortality and the $99.8 \% \mathrm{CI}$ excluded a benefit for salbutamol of the size anticipated in the protocol. The final analysis confirmed that intravenous salbutamol increased 28-day mortality (salbutamol group 34.2\% [55/161], placebo group $23.3 \%$ [38/163]; risk ratio 1.47 , 95\% CI 1.03-2.08). The increase in mortality was associated with a reduction in the number of ventilator-free days (mean difference -2.7 days, $95 \% \mathrm{CI}-4.7$ to -0.7 days) and organ failure-free days (mean difference -2.3 days, $95 \%$ CI -4.5 to -0.1 days). The risks of developing a tachycardia, new arrhythmia, or lactic acidosis severe enough to warrant stopping the study drug were substantially higher in the salbutamol group (23 [14.3\%] versus 2 [1.2\%]; risk ratio $11 \cdot 71,95 \%$ CI 2.81 to 48.88 ).

\section{Ongoing clinical trials}

A search of the International Standard Randomized Controlled Trial Number (ISRCTN) register and Clinicaltrials.gov for trials using $\beta$-agonists in ARDS identified two additional trials. The BALTI-prevention study is a double blind placebo controlled trial investigating whether inhalation of the long acting $\beta$-agonist salmeterol can prevent the development of ALI in patients undergoing esophagectomy (ISRCTN47481946) [34]. The trial completed recruitment in June 2011 and is due to report in 2012 when follow-up is complete. A second study, the Beta-agonists for Oxygenation in Lung Donors (BOLD) is testing the effect of nebulized salbutamol on oxygenation and lung transplantation rates in brain dead organ donors. This study has completed recruitment and is due to report shortly.

\section{What are the possible reasons for failure of $\beta$-agonists to improve outcomes in ARDS? Adverse cardiac effects}

Salbutamol is known to have arrhythmia- and tachycardiainducing properties. Traditional teaching is that $\beta$ adrenoceptors in the heart are of the $\beta-1$ subtype; however up to one third of the $\beta$-adrenoceptors in the atria and ventricles are $\beta-2$. The electrophysiological changes seen in patients treated with salbutamol are attributed to stimulation of these $\beta-2$ receptors. This myocardial stimulation has the potential to result in increased 
myocardial oxygen demand, with detrimental effects on myocardial function, especially in hypoxic ARDS patients. In a study of patients with acute severe asthma, of the 129 patients given inhaled salbutamol, there was an increase in the incidence of ventricular and supraventricular ectopic beats, but none of the patients had a clinically significant arrhythmia; this study excluded hypoxic patients, however [35]. In a large casecontrol study which enrolled elderly patients with chronic obstructive pulmonary disease (COPD), a dose response relationship was identified between prescription of a $\beta$-agonist and subsequent development of an acute coronary syndrome [36]. Many patients with critical illness have comorbid cardiovascular disease. It is, therefore, possible that some patients experienced adverse cardiovascular events including occult cardiac ischemia. These adverse effects may, therefore, limit any benefit associated with alveolar fluid balance.

\section{Vasodilatation}

Salbutamol is known to induce vasodilatation, an effect which precedes its bronchodilatory properties. This phenomenon and the increase in cardiac output cause an increase in ventilation/perfusion mis-match in patients when salbutamol is administered by the intravenous route. In a canine model of ALI, treatment with intravenous terbutaline increased cardiac index, aggravating capillary-alveolar macromolecular leakage [37]. A third possibility is the downregulation of $\beta$-agonist receptors (tachyphylaxis) during sustained treatment with $\beta$ agonists. Although most experimental studies suggest this is a minor factor it has been described in some models [38].

\section{Biochemical effects and lactic acidosis}

Biochemical effects of salbutamol are known to include the induction of hypokalemia and hypomagnesemia. The BALTI-1 trial showed no significant difference in plasma electrolyte concentrations between placebo treated and salbutamol treated groups. The risks of developing a tachycardia, new arrhythmia, or lactic acidosis, severe enough to warrant stopping the study drug, were substantially higher in the salbutamol group than in the placebo group in the BALTI-2 trial [33].

Lactic acidosis is also a recognized side effect of intravenous and nebulized $\beta_{2}$ agonists [39]. This effect is probably mediated by $\beta_{2}$-adrenoreceptors and is thought to be due to an increase in skeletal muscle glycogenolysis and a subsequent rise in peripheral lactate production. Splanchnic glucose production and lactate extraction are also increased, as a result of increases in hepatic glycogenolysis and gluconeogenesis. Acidosis does not develop until the bicarbonate buffering system is saturated, and this usually does not occur until lactate concentrations exceed $5 \mathrm{mmol} / \mathrm{l}$ [40]. In the BALTI-1 study there was no significant difference in the incidence of lactic acidosis between the placebo and treatment arms of the study, and no patients had their infusion discontinued because of lactic acidosis. It should be noted however that this study was not statistically powered to detect such a difference in this adverse event.

\section{Dosage and route of administration}

The nebulized route for administration of $\beta$-agonists is better tolerated with fewer adverse side effects than the intravenous route. However, a limitation of the nebulized route is the lack of certainty that the drug reaches the required site of action, particularly in the setting of ALI which is characterized by injured, fluid filled alveoli. Although the ALTA investigators had preliminary evidence that nebulized salbutamol achieved drug concentrations of $10^{-6} \mathrm{M}$ in undiluted pulmonary edema fluid [41], there remains uncertainty as to whether the drug reached the required site of action.

The dose of salbutamol used in the BALTI-2 trial $(15 \mu \mathrm{g} / \mathrm{kg} / \mathrm{h})$ was selected after an early dose ranging study identified it to be the maximum dose that critically ill patients could receive without an increase in ventricular, atrial tachycardia or ectopy. This dose was used in the BALTI-1 study and achieved plasma levels of salbutamol $\left(10^{-6} \mathrm{M}\right)$ [14] which are associated with a $100 \%$ increase in basal alveolar fluid clearance in animal models of ARDS. This dose is at the higher end of the manufacturer's recommended dosing regimen. It is possible, therefore, that a lower dose of salbutamol might have been better tolerated so the conclusions from the BALTI studies only relate to the dose given.

\section{Conclusion}

Over three decades of intense research activity has examined the potential role that $\beta$-agonists could play in the treatment of ARDS. Pre-clinical trials suggested that these drugs could accelerate alveolar fluid clearance, may have beneficial immunomodulatory effects and may reduce alveolar-epithelial permeability. A small phase 2 randomized controlled trial demonstrated proof of concept by showing that a sustained infusion of intravenous salbutamol reduced EVLW in patients with ARDS. Despite this preliminary evidence, the early promise has not held up to robust testing in the context of multicenter clinical trials. The ALTA trial was terminated on the grounds of futility after it became clear that salbutamol did not affect ventilator-free days. The BALTI-2 trial was terminated for similar reasons alongside concerns about safety and tolerability. Together these findings suggest that the routine administration of $\beta$-agonists as a treatment for ARDS should be avoided. 


\section{Abbreviations}

$\beta$-agonists, $\beta$-adrenoceptor agonists; AC, adenylate cyclase; ALI, acute lung injury; ALTA, AlbuteroL for the Treatment of ALI; ARDS, acute respiratory distress syndrome; BAL, bronchoalveolar lavage; BALTI-1, $\beta$-agonist Lung Injury Trial; BOLD, Beta-agonists for Oxygenation in Lung Donors; Cl, confidence interval; Cdyn, dynamic compliance; Cstat, static compliance; ENaC, amiloridesensitive $\mathrm{Na}^{+}$channel; EVLW, extravascular lung water; I-KB, inhibitor-kB; i.v intravenous; IL, interleukin; ISRCTN, International Standard Randomized Controlled Trial Number; LIS, lung injury score; LPS, lipopolysaccharide; MPO, myeloperoxidase; N/A, not available/applicable; NF-kB, nuclear factor-kB; OFFD, organ failure-free days; $\mathrm{P} / \mathrm{F}, \mathrm{PaO}_{2} / \mathrm{FiO}_{2}$; $\mathrm{PEEP}$, positive end-expiratory pressure; PKA, protein kinase A; RAGE, receptor for advanced glycation end products; ROS, reactive oxygen species; TNF, tumor necrosis factor; VFD, ventilator-free days; vWF, von Willebrand factor.

\section{Competing interests}

The authors declare that there are no competing interests.

\section{Acknowledgements}

We wish to thank Dr Park and Professor Gao for their helpful comments during the development of this review. CR Bassford is funded by the National Institute for Health Research Clinical Lecturer scheme; DR Thickett is funded by the Wellcome Foundation; GD Perkins is funded by a Clinician Scientist Award from the National Institute for Health Research.

\section{Author details}

'Division of Health Sciences, Clinical Trials Unit, University of Warwick, Coventry, CV4 7AL, UK. ${ }^{2}$ Critical Care Unit, Heart of England NHS Foundation Trust, Bordesley Green East, Birmingham, B9 5SS, UK. ${ }^{3}$ Lung Injury and Fibrosis Treatment Program, School of Clinical and Experimental Medicine, University of Birmingham, Birmingham, B15 2TH, UK.

Published: 20 March 2012

\section{References}

1. Ware LB, Matthay MA: The acute respiratory distress syndrome. N Engl J Med 2000, 342:1334-1349.

2. Adhikari N, Burns KE, Meade MO: Pharmacologic therapies for adults with acute lung injury and acute respiratory distress syndrome. Cochrane Database Syst Rev 2004, CD004477.

3. The Acute Respiratory Distress Syndrome Network: Ventilation with lower tidal volumes as compared with traditional tidal volumes for acute lung injury and the acute respiratory distress syndrome. N Engl J Med 2000 342:1301-1308.

4. Wiedemann HP, Wheeler AP, Bernard GR, et al:: Comparison of two fluidmanagement strategies in acute lung injury. N Engl J Med 2006, 354:2564-2575

5. Zambon M, Vincent JL: Mortality rates for patients with acute lung injury/ ARDS have decreased over time. Chest 2008, 133:1120-1127.

6. Perkins GD, McAuley DF, Richter A, Thickett DR, Gao F: Bench-to-bedside review: beta2-Agonists and the acute respiratory distress syndrome. Crit Care 2004, 8:25-32.

7. Johnson M: Molecular mechanisms of beta(2)-adrenergic receptor function, response, and regulation. J Allergy Clin Immunol 2006, 117:18-24.

8. Mutlu GM, Factor P: Alveolar epithelial beta2-adrenergic receptors. Am J Respir Cell Mol Biol 2008, 38:127-134.

9. Ware LB, Matthay MA: Alveolar fluid clearance is impaired in the majority of patients with acute lung injury and the acute respiratory distress syndrome. Am J Respir Crit Care Med 2001, 163:1376-1383.

10. Berthiaume Y, Matthay MA: Alveolar edema fluid clearance and acute lung injury. Respir Physiol Neurobiol 2007, 159:350-359

11. Sakuma T, Folkesson HG, Suzuki S, Okaniwa G, Fujimura S, Matthay MA: Betaadrenergic agonist stimulated alveolar fluid clearance in ex vivo human and rat lungs. Am J Respir Crit Care Med 1997, 155:506-512.

12. Dumasius V, Sznajder Jl, Azzam ZS, et al:: $\beta 2$-Adrenergic receptor overexpression increases alveolar fluid clearance and responsiveness to endogenous catecholamines in rats. Circ Res 2001, 89:907-914.

13. Grommes J, Soehnlein O: Contribution of neutrophils to acute lung injury. Mol Med 2011, 17:293-307.

14. Perkins GD, Nathani N, McAuley DF, Gao F, Thickett DR: In vitro and in vivo effects of salbutamol on neutrophil function in acute lung injury. Thorax
2007, 62:36-42.

15. Bloemen PG, van den Tweel MC, Henricks PA, et al:: Increased cAMP levels in stimulated neutrophils inhibit their adhesion to human bronchial epithelial cells. Am J Physiol 1997, 272:L580-L587.

16. Maris NA, de Vos AF, Dessing MC, et al:: Antiinflammatory effects of salmeterol after inhalation of lipopolysaccharide by healthy volunteers. Am J Respir Crit Care Med 2005, 172:878-884.

17. Farmer P, Pugin J: beta-adrenergic agonists exert their "anti-inflammatory" effects in monocytic cells through the IkappaB/NF-kappaB pathway. Am J Physiol Lung Cell Mol Physiol 2000, 279:L675-L682.

18. Tan KS, Nackley AG, Satterfield K, Maixner W, Diatchenko L, Flood PM: Beta2 adrenergic receptor activation stimulates pro-inflammatory cytokine production in macrophages via PKA- and NF-kappaB-independent mechanisms. Cell Signal 2007, 19:251-260.

19. Minnear FL, DeMichele MA, Moon DG, Rieder CL, Fenton JW: Isoproterenol reduces thrombin-induced pulmonary endothelial permeability in vitro. Am J Physiol 1989, 257:H1613-H1623.

20. Takashima S, Schlidt SA, Koukoulis G, Sevala M, Egan TM: Isoproterenol reduces ischemia-reperfusion lung injury despite beta-blockade. J Surg Res 2005, 126:114-120

21. Perkins GD, Gao F, Thickett DR: In vivo and in vitro effects of salbutamol on alveolar epithelial repair in acute lung injury. Thorax 2008, 63:215-220.

22. Basran GS, Hardy JG, Woo SP, Ramasubramanian R, Byrne AJ: Beta-2adrenoceptor agonists as inhibitors of lung vascular permeability to radiolabelled transferrin in the adult respiratory distress syndrome in man. Eur J Nucl Med 1986, 12:381-384.

23. Pesenti A, Pelosi P, Rossi N, Aprigliano M, Brazzi L, Fumagalli R: Respiratory mechanics and bronchodilator responsiveness in patients with the adult respiratory distress syndrome. Crit Care Med 1993, 21:78-83.

24. Wright PE, Carmichael LC, Bernard GR: Effect of bronchodilators on lung mechanics in the acute respiratory distress syndrome (ARDS). Chest 1994, 106:1517-1523.

25. Morina P, Herrera M, Venegas J, Mora D, Rodriguez M, Pino E: Effects of nebulized salbutamol on respiratory mechanics in adult respiratory distress syndrome. Intensive Care Med 1997, 23:58-64

26. Manocha S, Gordon AC, Salehifar E, Groshaus H, Walley KR, Russell JA: Inhaled beta-2 agonist salbutamol and acute lung injury: an association with improvement in acute lung injury. Crit Care 2006, 10:R12.

27. Perkins GD, McAuley DF, Thickett DR, Gao F: The beta-agonist lung injury trial (BALTI): a randomized placebo-controlled clinical trial. Am J Respir Crit Care Med 2006, 173:281-287.

28. Licker M, Tschopp JM, Robert J, Frey JG, Diaper J, Ellenberger C : Aerosolized salbutamol accelerates the resolution of pulmonary edema after lung resection. Chest 2008, 133:845-852.

29. Craig TR, Duffy MJ, Shyamsundar M, et al.: Extravascular lung water indexed to predicted body weight is a novel predictor of intensive care unit mortality in patients with acute lung injury. Crit Care Med 2010, 38:114-120.

30. Effros RM: The beta-agonist lung injury trial (BALTI). Am J Respir Crit Care Med 2006, 173:1290.

31. Matthay MA, Brower RG, Carson S, et al:: Randomized, placebo-controlled clinical trial of an aerosolized beta-2 agonist for treatment of acute lung injury. Am J Respir Crit Care Med 2011, 184:561-568.

32. Perkins GD, Gates S, Lamb SE, McCabe C, Young D, Gao F: Beta Agonist Lung Injury Trlal-2 (BALTI-2) trial protocol: a randomised, double-blind, placebocontrolled of intravenous infusion of salbutamol in the acute respiratory distress syndrome. Trials 2011, 12:113.

33. Smith FG, Perkins GD, Gates S, et al:: The effect of intravenous beta-2 agonist therapy on clinical outcomes in the acute respiratory distress syndrome (BALTI-2): a multicentre, randomised controlled trial. Lancet, in press.

34. Perkins GD, Park D, Alderson D, et al:: The Beta Agonist Lung Injury Trlal (BALTI)-prevention trial protocol. Trials 2011, 12:79.

35. Newhouse MT, Chapman KR, McCallum AL, et al:: Cardiovascular safety of high doses of inhaled fenoterol and albuterol in acute severe asthma. Chest 1996, 110:595-603.

36. Au DH, Curtis JR, Every NR, McDonell MB, Fihn SD: Association between inhaled beta-agonists and the risk of unstable angina and myocardia infarction. Chest 2002, 121:846-851.

37. Briot R, Bayat $S$, Anglade D, Martiel JL, Grimbert F: Increased cardiac index due to terbutaline treatment aggravates capillary-alveolar macromolecular leakage in oleic acid lung injury in dogs. Crit Care 2009, 
13:R166.

38. Abel SJ, Finney SJ, Brett SJ, Keogh BF, Morgan CJ, Evans TW: Reduced mortality in association with the acute respiratory distress syndrome (ARDS). Thorax 1998, 53:292-294.

39. Stratakos G, Kalomenidis J, Routsi C, Papiris S, Roussos C: Transient lactic acidosis as a side effect of inhaled salbutamol. Chest 2002, 122:385-386.

40. Day NP, Phu NH, Bethell DP, et al.: The effects of dopamine and adrenaline infusions on acid-base balance and systemic haemodynamics in severe infection. Lancet 1996, 348:219-223.
41. Atabai K, Ware LB, Snider ME, et al:: Aerosolized beta(2)-adrenergic agonists achieve therapeutic levels in the pulmonary edema fluid of ventilated patients with acute respiratory failure. Intensive Care Med 2002, 28:705-711.

doi:10.1186/cc11221

Cite this article as: Bassford CR, et al:: The rise and fall of $\beta$-agonists in the treatment of ARDS. Critical Care 2012, 16:208. 